\title{
Laser Hardening Influence of Metal Surfaces
}

\author{
CARMEN OTILIA RUSANESCU1, MARIN RUSANESCU2*, COSMIN J INESCU ${ }^{3}$, SORIN STEFAN BIRIS ${ }^{1}$ \\ 1Politehnica University of Bucharest, Faculty of Biotechnical Systems Engineering, 313 Splaiul Independentei, 060042, Bucharest, \\ Romania \\ ${ }^{2}$ Valplast Industrie, 9 Preciziei Blvd., 062202, Bucharest, Romania \\ 3Politehnica University of Bucharest, Faculty of Mechanical Engineering, 313 Splaiul Independentei, 060042, Bucharest, Romania
}

\begin{abstract}
In this paper we analyze the influence of the number of laser pulses on the hardness of the metal. We have shown that the hardness increases with the number of laser pulses due to the increase in the probe surface temperature, especially by increasing the superficial absorption of laser radiation. Optical microscopy was analyzed by the metallographic aspects of the target in OLT 65, Al, Cu, laser irradiated
\end{abstract}

Keywords: Surface hardening, steel, Nd: YAG pulsed laser

Using the laser for the heating process of materials with applications towards the thermal surface treatment implies restrictive conditions on choosing the right irradiation laser parameters or on preventing phase changes in materials structure [1].

Improving the hardness of metal materials due to thermal treatment is the result of structural metalographic constituents changes due to the thermal transformations produced by laser. These transformations give rise to the transitory phase in solid state, implying that metal should be brought to a supersaturating local state. This state is obtained by heating the material at certain temperatures; afterwards, the material is cooled up suddenly for preventing the diffusion process, the equilibrium state reaching, respectively.

It is to be mentioned the fact that a disadvantage of the laser thermal treatment is that the treatment can be made only locally, on small dimensions surfaces [7-9].

When determining the laser thermal treatment parameters, the heating temperature respectively, $\mathrm{T}_{i}$ and the heating intervals $t$, for constant temperatures $t_{m}$, and cooling $t_{r}$, the transformations generated in the material for improving its properties, must be taken into account (fig. 1).

This concept implies a good knowledge of the critical transformation points for each material and in relation to these a good choice of the appropriate temperature. The evaluation of these temperatures can be made in several modes: using the equilibrium diagrams, by empiric or semi empiric relations out of classic thermal treatments or by experiments [3].

The heating temperature of the target surface and the penetration depth of material can be varied by regulating the beam power, the laser pulse width and in the case of controlled relative motion of the probe with respect to the

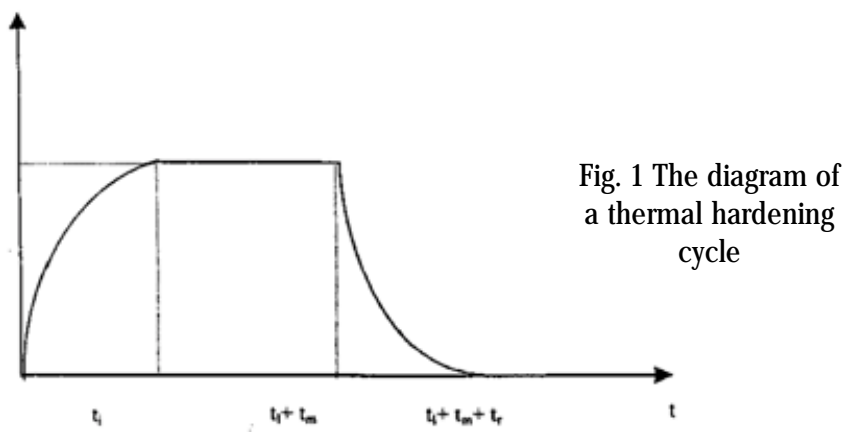

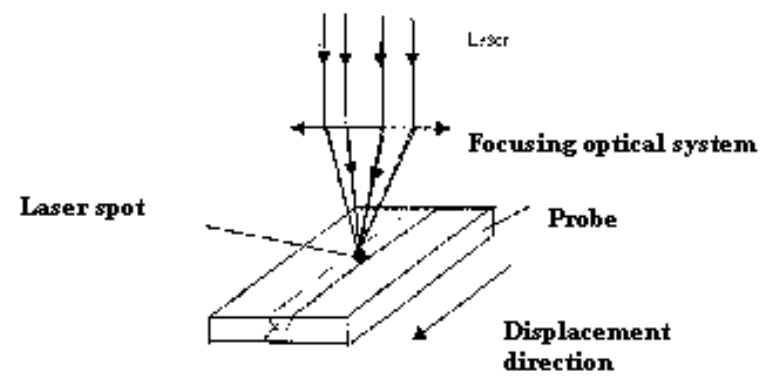

Fig.2 The laser thermal hardening in geometry, for relative movement of the target in relation to the laser fascicle [7]

laser beam by modifying the scanning velocity onto the target (fig. 2) [12-15].

The block diagram of a laser technology system is shown in the figure 3.

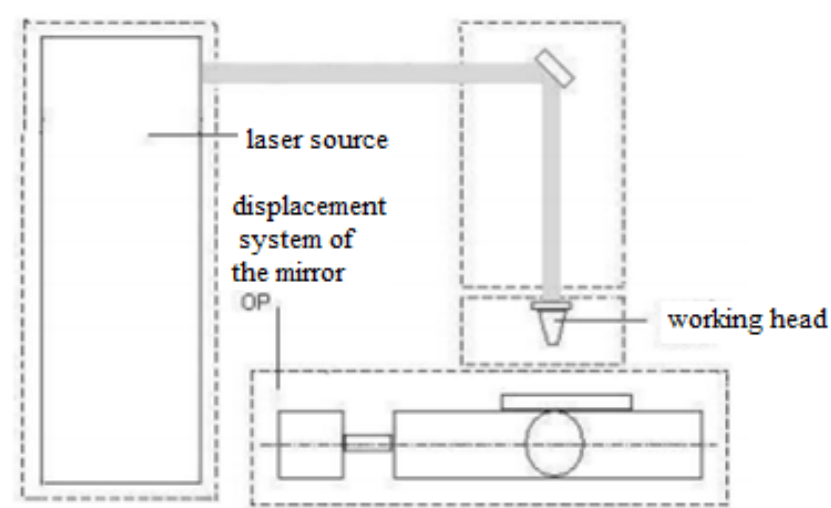

Fig. 3 Block diagram of a laser technology system [4]

The thickness of the thermally treated layer depends greatly on the thermal conductibility of the target material.

In case of thermal hardening, the intensity of laser radiations must be lower than those which generate the phase transformation [8-11].

The target surface positioning can be made under the focal plane (positive defocusing +Df), above the focal plane (negative defocusing-Df), or in focal plane (null defocusing), (fig. 4).

The experiments showed that the defocusing is a parameter which influences the heating temperature, the affected area and the penetration depth of the heat in the metal target.

Under constant laser irradiation conditions, in first domain $\in(5.5-9.5) \times 10^{3} \mathrm{~W} / \mathrm{cm}^{2}$ and the laser pulses

\footnotetext{
* email: rusanescum@yahoo.com; Phone: 0724330350; cosmin.jinescu@yahoo.com; Phone: 0731306908
} 


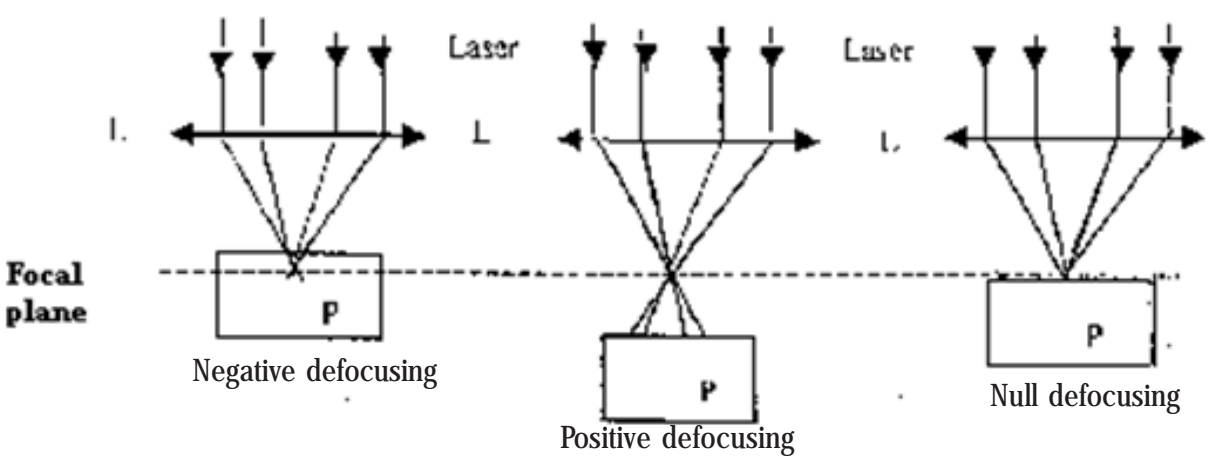

widths $\tau_{p} \in(1.65-6.5) \times 10^{-3} \mathrm{~s}$, the effect is max; which means that the induced hardening in the target has the greatest values when a positive defocusing $+\Delta f \in(1,4)$ $\mathrm{mm}$ takes place.

\section{Experimental part \\ Materials and methods}

A Nd: YAG laser with wavelength of $1064 \mathrm{~nm}$ was used for the experimental study of thermal laser hardening. The laser works on Q-Switch pulses, whose time intervals can be of $5 \mathrm{~ns}$, at an adjustable repetition frequency up to $10 \mathrm{~Hz}$. The pulses shape is gaussian, but in order to simplify the calculi concerning the thermal diffusion depth and the laser radiation threshold intensity necessary for superficial melting, we have supposed the pulse shape is rectangular. The pulse energy is $400 \mathrm{~mJ}$, the average value of laser power is $4 \mathrm{~W}$. At a max focusing, the diameter of laser fascicle is $0,3 \mathrm{~mm}$, resulting a value of laser radiations intensity of $\sim 0,44 \times 10^{6} \mathrm{~W} / \mathrm{cm}^{2}$.

The device is shown in figure 5 .

\section{Results and discussions}

A quart lens has been used for focusing. The targets have been made of Al, $\mathrm{Cu}$, Quartz and a kind of steel: OLT 65. The chemical compositions of the targets are shown in tables 1, 2, 3 .

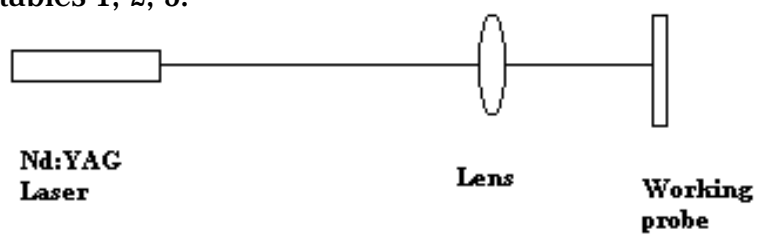

Fig. 5. Scheme the device used in experiments

\begin{tabular}{|l|l|l|l|l|}
\hline Probe & A1 & Cu & Cuarţ & OLT65 \\
\hline Hardness HV 3 & 5.55 & 7.65 & 11.4 & 8.20 \\
\hline
\end{tabular}

The target had a cylindric form, 1.5-2 mm thickness, 10 $\mathrm{mm}$ in diameter. The surface that was to be irradiated had been polished with alumina and then, the incidence spot of the laser fascicle on the target had been painted with a thick layer of black paint to increase the absorption of laser radiation. The experiments have been made under normal conditions and positive laser defocusing.

The measured values of the targets hardness before the laser irradiation are given in table 1. In order to measure the hardness, a microhardnessmeter has been used: Micro hardness Tester Shimadzu, using a diamond pyramidal penetrator with an angle of $136^{\circ}$, exerting a pressure of 3 $\mathrm{kg}$, the applied force was of $30 \mathrm{~N}$ for $15 \mathrm{~s}$.

The depth of thermal diffusion is $0.08-0.16 \mathrm{~mm}$. If the diameter of the irradiated area is greater than the order of magnitude, the approximation of the irradiated semi-space on the entire area is at least satisfied near the focal point. The results are shown in table 2 and figure 6.

The targets were metalographically prepared according to STANDARD 4203-74 and irradiated with 300 laser pulses [6]. The structural aspects of the material were determined by an increase order of 100, according to SR 5000: 1997 [5].

The next constituents were obtained according to STANDARD 500-1997 [5].

It can be seen from figure 7 for aluminum, the metallographic structure was the austenitic granularity grain size, for OLT 65, the structure was perforated, for $\mathrm{Cu}$, the structure was superior bainite.

\begin{tabular}{|l|l|l|l|l|}
\hline Pulses number & 300 & 600 & 900 & 1200 \\
\hline $\mathrm{A} 1$ & $6.00 \mathrm{HV}_{3}$ & $6.65 \mathrm{HV}_{3}$ & $7.32 \mathrm{HV}_{3}$ & $7.94 \mathrm{HV}_{3}$ \\
\hline $\mathrm{Cu}$ & $7.97 \mathrm{HV}_{3}$ & $8.23 \mathrm{HV}_{3}$ & $8.72 \mathrm{HV}_{3}$ & $9.08 \mathrm{HV}_{3}$ \\
\hline OLT 65 & $8.30 \mathrm{HV}_{3}$ & $8.58 \mathrm{HV}_{3}$ & $8.97 \mathrm{HV}_{3}$ & $9.37 \mathrm{HV}_{3}$ \\
\hline Quartz & $11.50 \mathrm{HV}_{3}$ & $11.63 \mathrm{HV}_{3}$ & $11.79 \mathrm{HV}_{3}$ & $11.98 \mathrm{HV}_{3}$ \\
\hline
\end{tabular}

Table 1

VALUES OF HARDNESS OF METAL TARGETS BEFORE THE LASER IRRADIATION 

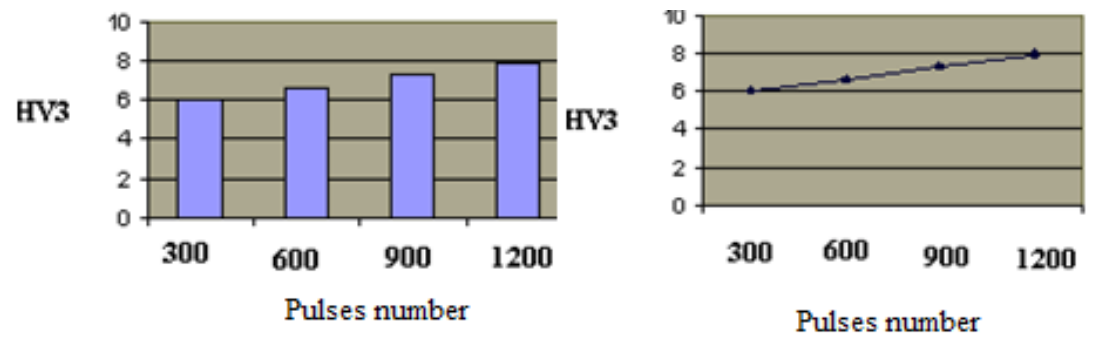

Fig. 6 a. Surface hardness in $\mathrm{Al}$
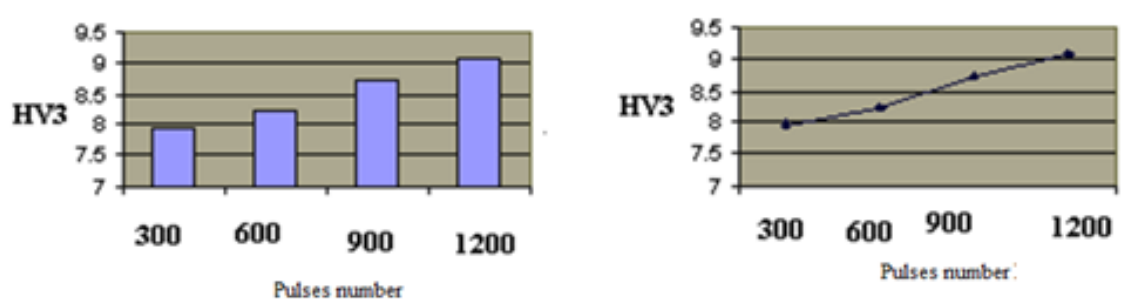

Fig. $6 \mathrm{~b}$. Surface hardness in $\mathrm{Cu}$
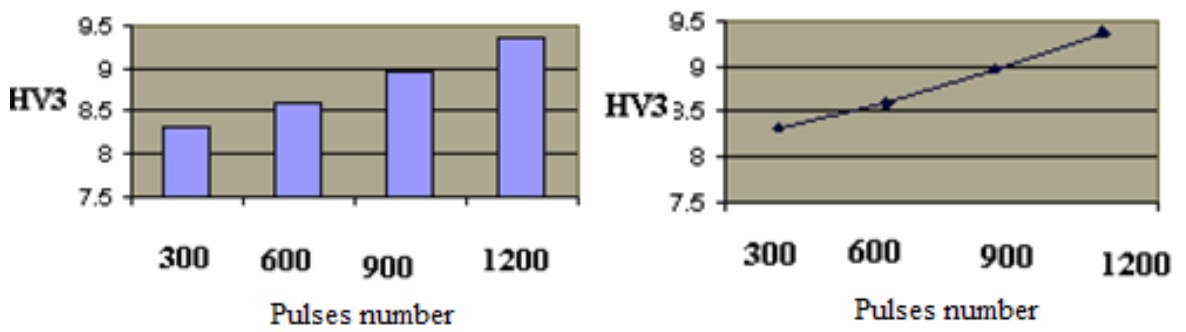

Fig. 6 c. Surface hardness in OLT 65

F
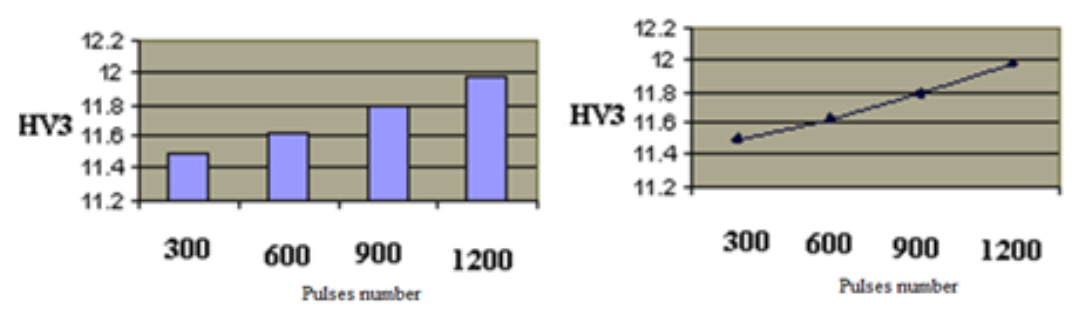

Ises

Fig. 6 d. Surface hardness in Quartz

Fig. 6 The dependence of surface hardness of some metal targets, on the numbers of laser pulses

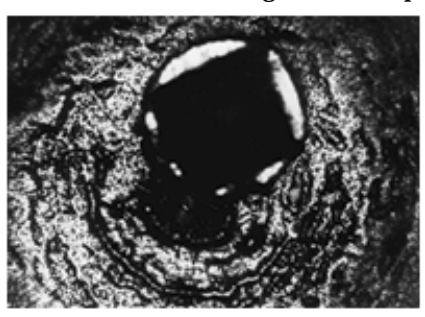

$\mathrm{Cu}$

\section{Nital Attack $2 \% \times 100$}

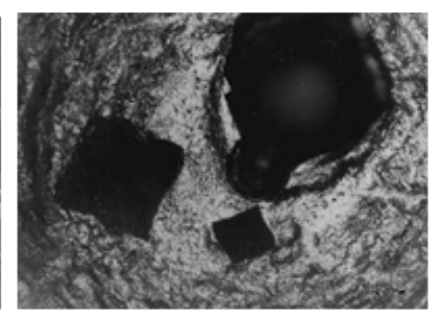

Al

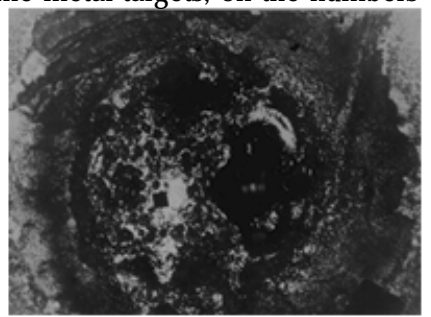

OLT 65
Fig. 7 Microscopic aspects of the irradiated target (Nd:YAG laser - 300 Pulses)

\section{Conclusions}

In the present paper from the experiments we can see that the hardness increases with the increase of the number of laser pulses due to the increase of the probe surface temperature, especially by the increase of the superficial absorption of the laser radiation. Materials from aluminum, copper, quartz, OLT 65 were studied. The microscopic

aspects of the target from OLT 65, $\mathrm{Al}, \mathrm{Cu}$, were laser irradiated. The metallographic structure was for Al grain austenite grain boundary, for OLT 65, the structure was perlite troosttite, for $\mathrm{Cu}$, the structure was superior bainite. The hardness values of the metal targets were determined prior to laser irradiation. 


\section{References}

1. DAVIS, M., KAPADIA, P., DOWDEN, J., STEEN, W. M., COURTNEY, C.H.G., J ournal of Physics D: Applied Physics, 19, 10, 1986.

2. CHARLES S.MONTROSS, TAOWEI, LINYE, GRAHAMCLARK, YIUWINGMAI, International J ournal of Fatigue, 24, 10, 1021-1036, 2002. 3. CAZACU, N., SAVA, L., DOBROVICl, S., BACLEA, A., The annals of Dunarea de JoS University of Galati. fascicle IX. Metallurgy and Materials Science, 1, 2008.

4.CHRYSSOLOURIS, G., Laser machining, Theory and Practice, Springer-Verlag, New-York, 1991.

5. *** SR 5000:1997 Structures and metallographic constituents of ferrous products

6. *** STAS 4203-74 Taking and preparing metallographic samples

7. DONTU, O., Laser processing technologies, 106, 1985.

8. R.KOMANDURI, Z.B.HOU, International Journal of Heat and Mass Transfer, 44, 15, 2845-2862, 2001
9. JAE-HOLEE, JEONG-HWAN, J ANGBYEONG-DON, JOOYOUNG-MYUNG SONYOUNG-HOON MOON, Transactions of Nonferrous Metals Society of China, 19, 4, 917-920, 2009.

10. PEDRO DE LA CRUZ, MAGNUS ODENTORSTEN ERICSSON, International J ournal of Fatigue, 20, 5, 389-398, 1998.

11.PATRICE PEYRE, C. CARBONI, P. FORGET, G. BERANGER, C. LEMAITRE, D. STUART, J ournal of Materials Science, 42, 16, 6866-6877, 2007.

12. IZHAK ETSION, J. Tribol 127, 1, 248-253, 2005.

13. SLATTER, T., TAYLOR, H, LEWIS, R, KING, P, Wear, 267, 5-8, 797806, 2009.

14. MAHMOUDI, B, TORKAMANY, M.J ., SABOUR, A.R., ROUH AGHDAM, SABBAGHZADE, J, Materials Design, 31, 2553-2560, 2010.

15. PINTO, M. A., NOE CHEUNG, MARIA CLARA FILIPPINI IERARDI, AMAURI GARCIA, Materials Characterization, 50, 2-3, 249-253, 2003.

Manuscript received: 22.01 .2018 